\title{
ENTREVISTA COM LÍDIA JORGE: “A LITERATURA TEM UM PODER LENTO, MAS É UM PODER SEGURO”.
}

\author{
Mauro Dunder ${ }^{1}$
}

\begin{abstract}
APRESENTAÇÃO: O poder das palavras, a relação entre literatura e questões sócio-históricas, a busca ontológica do autor. Em entrevista concedida em julho de 2012, a escritora aborda estas e outras questões relevantes, como a crise do romance na contemporaneidade, a relação entre o povo português, seu presente e os ecos da Revolução dos Cravos e o percurso percorrido por ela ao compor sua obra romanesca.
\end{abstract}

Com a espontaneidade e a doçura que lhe são características, Lídia Jorge conversou com o pesquisador durante mais de três horas, na Casa das Courelinhas, residência que guarda laços com a história da vinicultura do Algarve. Desse encontro, a Desassossego reproduz aos seus leitores alguns dos (muitos) trechos mais significativos.

LIDIA JORGE: "LITERATURE HAS A SLOW POWER, BUT IT IS A SAFE ONE."

PRESENTATION: The power of the words, the relations between literature and social and historical issues, the personal search of an author. In this interview, made in July, 2012, the Portuguese writer deals with those questions, amongst others, such as the crisis of the contemporary novel, the relations between the Portuguese, their present days and the echoes of the Carnation Revolution (1974), as well as the path run by her while building her novelistic work.

In a spontaneous and sweet way, so typical of hers, Lídia Jorge talked to the researcher for over three hours, at the Casa das Courelinhas, a house which keeps connections with the vinery history in the Portuguese region of the Algarve. From those moments, Desassossego provides its readers with some of the (many) meaningful moments.

\footnotetext{
${ }^{1}$ Doutorando em Letras, aluno do Programa de Pós-Graduação em Literatura Portuguesa. A viagem a Portugal, para que esta entrevista se realizasse, foi custeada integralmente pela Pró-Reitoria de PósGraduação (PRPG) da USP.
} 
MD: 32 anos depois de sua publicação, de que maneira $O$ dia dos prodígios ainda repercute em sua vida e em Portugal?

LJ: Na minha vida, de uma forma muito funda, tão profunda que eu tenho a ideia de que foi um livro que abriu o ciclo da publicação para mim, e tenho a ideia de que, enquanto eu não escrever um livro que seja a resposta do tempo a $\mathrm{O}$ dia dos prodígios, isto não está completo. Porque $\mathrm{O}$ dia dos prodígios foi uma espécie de fascínio interior que eu tive, numa altura em que eu percebia que a literatura tinha campos tão vastos, e eu escolhi um campo que, a princípio, seria uma derrota à partida, porque tinha o aspeto tradicional, que não estava mais na moda, porque era sobre a questão da nacionalidade, que também não estava mais na moda, porque eu utilizava métodos que tinham sido utilizados, nomeadamente os linguísticos, que tinham sido utilizados pelos neorrealistas, e que eu iria outra vez incorporar - mas que também não estavam mais na moda, e, no entanto, com essa consciência de que era uma coisa que, digamos, era uma espécie de badalada sobre o passado, eu tive uma ideia de que era preciso escrever alguma coisa sobre um país que iria mudar, e cuja última visão era aquela, de um passado que tinha sido de uma coerência brutal, terrivel, mas que essa coerência iria desaparecer. E eu escrevi esse livro, agora olho para trás e penso que foi o livro mais generoso que eu escrevi, porque escrevi com a ideia de que estava a fazer um livro para não esquecer, apenas para não esquecer.

Poderia, possivelmente, escrever outros, mas a minha ideia era a de um livro para não esquecer um povo, uma pátria, um modo de ser, para não esquecer uma cultura e uma civilização. E fazia isso pondo pazadas de terra sobre uma espécie de cadáver. Ora, o que aconteceu foi que, ao publicar o livro, os leitores me disseram que era um livro-síntese sobre a cultura portuguesa, com uma proposta de leitura para o futuro. Passaram esses anos todos, foi possível voltar com ele, a (atriz e diretora teatral) Cucha Carvalheiro pô-lo em teatro, foi uma peça, para mim, muito comovente e penso que foi muito comovente para muitas pessoas. A sensação que muita gente teve expressou foi que voltava a ser uma leitura do país outra vez. E eu tive essa ideia de que todo o lado críptico e interno e passado do livro, que se tornou apenas poético, transformou-se nalguma coisa que explica porque somos hoje assim, porque não evoluímos o que quisemos, porque mantemos 
determinadas qualidades ainda e, sobretudo, porque mantemos um traço que nos é próprio, e que deriva desse livro, que é, o português seja um povo com demasiada força no sonhar e demasiada debilidade no agir, e isto voltou outra vez a ser visto e ser falado. Então, eu tenho essa ideia de que houve uma espécie de prenda que a vida me deu, em relação a esse livro, é um livro que me dá gratidão e que, de certa forma, me ajuda a dar uma espécie de coerência a tudo que eu tenho feito, ainda que muitos leitores digam que eu mudei muito, e eu acho que não mudei muito. Acho que mudei só na parte acidental, o essencial está n'O dia dos prodígios.

MD: Você me disse, agora há pouco, que é um livro que provoca em você o desejo de buscar uma resposta. A quê?

LJ: O livro O dia dos prodígios é feito com um enigma sobre o ser. De facto, sou uma escritora em que, por mais que não queira, minha parte ontológica é social. E, passado este tempo, eu tenho a ideia de que o mesmo enigma - que nunca nasce do drama individual das pessoas, mas do coletivo, do drama de um indivíduo na trama da relação com os outros -, essa espécie de quarto obscuro, onde eu procuro um sentido para um indivíduo, possivelmente, é para minha própria existência, mas que eu nunca vejo desligada duma totalidade, dum grupo. Eu continuo com a mesma dúvida, quer dizer, para que serve isto? Para que serve isto, que rosto está por trás disto? Tenho muito a ideia de que - aliás, aqui neste sítio onde nós estamos a conversar, tenho a ideia, vou até meu trisavô, meu pentavô -, de que cada um de nós fazemos parte duma espécie duma sequência, de onde a onde que se vem um indivíduo, que tem um nome diferente, olhar para a mesma realidade. E esse enigma, que no fundo é da corrente humana, eu mantenho esse mesmo enigma, mas como não sou filósofa, que põe em abstrato, ponho em concreto e no particular, que é a terra onde estou: este país de mar, que, no entanto, é fortemente rural, com todo este complexo de que, no passado, dominamos o mar e, no presente, somos dominados por todos, inclusive, por nosso próprio sonho amarfanhado. Então, eu tenho, digamos, a ideia de que preciso de continuar a responder a esta pergunta que eu faço n'O dia dos prodígios, que é "que destino é este? Para que este destino?”. E acho que eu tenho tentado fazer isso em todos os livros desde aí, de uma forma fragmentada e eu acho que 
precisava - não sei se serei capaz, se não for, é, enfim, porque não sou - mas tenho essa ambição de escrever um livro, digamos, onde eu volte a fazer a mesma interrogação. Não digo que tenha a resposta, mas consiga fazer a interrogação bem articulada com todas as teclas do meu piano.

MD: Muito se fala sobre a crise do gênero romance na contemporaneidade. Considera o romance um gênero extinto, ou em via de extinção?

LJ: Não. Sou sincera, não o considero em vias de extinção. Considero que continua a ser o género maior, mas que ele está num ambiente de grande adversidade, porque é feito para aquilo que nós podemos chamar de "o nosso cérebro lento" e tudo hoje está organizado de forma a nós exercitarmos, sobretudo, “o nosso cérebro rápido”. Além disso, o mundo de hoje continua a ser poético, mas em pequenas doses, como se só se conseguisse absorver a poética parcelada; por isso, a poesia, inclusive, parece até ser um género que pode vir a ter, nos próximos momentos, mais resposta e mais acolhimento do que propriamente o romance. E, portanto, até neste ponto de vista fragmentário, o romance tem essa adversidade, sua estrutura é pouco compaginada com a poética do momento, não é? A poética do momento, eu diria, é a poética da canção, da letra da canção, aquela que não se basta só a si, que precisa de ter atrás de si a música, outra música, a dança, toda a parafernália, e que, portanto, a poética da palavra é um ingrediente para o resto.

Inclusive, existe hoje, digamos, um grande desejo de ficar à meia haste com o romance histórico, que é, digamos, um gênero muito importante, mas é um gênero híbrido, que falseia o que é o romance, porque vive de uma outra realidade, enquanto o romance tem de se bastar por si próprio, não é? Tem de criar sua própria transfiguração, a sua própria poética. E ele tem de ser, mesmo quando vai à história, ou é muito contemporâneo, que corre a actualidade, mas tem de se bastar a si próprio, quer dizer, a poética que tem de ser mais forte do que aquilo que é, digamos, o seu contexto, não é?

MD: Há, ao longo da sua obra, algumas referências, alguns debates históricos bastante fortes. Especificamente sobre $A$ costa dos murmúrios, parece-me que ali se ilumina um anacronismo do pensamento português em relação à manutenção das colônias, da maneira como aconteceu 
pouco antes e pouco depois do 25 de Abril. Isso se discute em Portugal hoje? Portugal ainda se ressente da independência das suas colônias, administra alguma mágoa em relação a isso, ou não, hoje convive com o fato de que não é mais “o império das colônias”?

LJ: Olha, é uma questão que se discute muito, e discute-se sobre a ideia de que estamos no divã do psicanalista e ainda não demos, ele ainda não nos deu, a resposta sobre se ainda nos dói ou já não nos dói, não é? Mas a verdade é que, olhando para a população, eu acho que há sentimentos mistos. Haverá pessoas que ainda estão muito ressentidas com o que aconteceu, que consideram que os males de Portugal radicam nessa perda e, portanto, ainda estão equacionando a questão olhando para trás. Penso, por aí, que não é a maior parte dos portugueses, que convive com uma nova realidade, a de que os países estão bem e que estão independentes, e de que é preciso manter laços, novos laços, digamos, de relações normais, com países que se entendem muito mais do que como colonizados e colonizadores. E eu acho que isto é uma das facetas positivas da actualidade, as novas gerações falarem descomplexadamente dessa situação, mesmo as pessoas da minha idade, que desejaram a descolonização, ou melhor, perceberam que era um anacronismo, que era alguma coisa que Portugal mantinha fora da história. Portanto, passado este tempo todo, o que nós temos pena é de Portugal não ser um país mais próspero do que é, e de que as excolônias tivessem se envolvido, como países autônomos, em guerras, em disputas e em simulacros, ou não, verdadeiros estados que são ainda muito próximos dos ditatoriais, que os povos não sejam ainda povos desenvolvidos como queremos, mas parece que a situação está praticamente debelada.

Acho que caminhamos no sentido em que o ressentimento é muito menor do que o sentimento, que é positivo, e isso, na arte, está perfeitamente patente, na música, na ligação que Portugal faz hoje em dia com o Brasil, naturalmente, mas o Brasil faz ligação com todo mundo, não é? Mas, digamos, a forma como aqui se recebe e se junta, acho que os portugueses têm muitos defeitos, mas acho que não têm o defeito de não querer receber de volta essa espécie de regresso de caravelas. Acho que os portugueses o fazem, hoje em dia, de uma forma bem, moderna. É aquilo para que a humanidade do futuro tende, não é? Acho isso. E acho que a literatura tem um poder lento, não é, mas é um poder seguro. A 
literatura vai criando... Veja, eu nunca me esqueci da história da Lindinalva e do negro Balduíno, não é? Quer dizer, essa história ficou para toda a vida, não penso todos os dias, mas foi uma história tão marcante, de quando era miúda, que a história me mantém, como uma história de ternura, de amor, que me tocou, e eu acho que a literatura é isso, literatura faz esse caminho lento, demorado, na alma das pessoas.

MD: Você me perdoe se essa pergunta já tiver sido feita a você infinitas vezes, mas...

LI: (Risos)... Mas a resposta nunca é igual, sabe, e não sei se não será contraditória...

MD: (Risos) Julga que a geração de escritores que surgiu depois do 25 de Abril tinha conscientemente o papel de retomar a identidade portuguesa e tentar debatê-la?

LJ: Não... Não, não tinha, não. Acho que cada um começou a gritar para o seu lado. Quer dizer, cada um começou a escrever para o seu lado. Aliás, lembro muito bem, alguns dos debates foram até feitos no Brasil sobre isso, cada um tinha a sua história, tinha a sua visão, aquilo que lhe ia na alma, e é a primeira vez que, digamos assim, cada escritor aparece com a sua personalidade, despegado de escolas, porque até aí, inclusive por circunstâncias, e não só em Portugal, um pouco por toda a parte, os escritores inscreviamse em grupos, e depois, quando não se inscreviam, respondiam contrariamente a um grupo, mas havia sempre a referência, era como se houvesse o rebanho e as suas ovelhas ranhosas, mas organizavam-se dessa forma.

O que acontece, depois do 25 de Abril em Portugal, é uma explosão, de facto, de personalidades, umas mais fortes, outras mais fracas, mas são figuras que, muitas vezes, encontram parceiros em sítios longínquos, não propriamente em Portugal, quer dizer, cada um a procurar parceiros anímicos, do ponto de vista da escrita, mais do que propriamente parceiros de escolas. E a questão de debater a identidade, ninguém usou o que escreveu para debater a identidade, mas eu vinha com a questão de África, porque tinha vivido; vinha com a questão do 25 de Abril, porque aqui nesta terra eu fui testemunha de uma transformação que foi mágica, que foi extraordinária, que foi magnífica, que foi surreal. Tinha, digamos, uma visão da mudança do estatuto das mulheres, pela minha própria 
história, quer dizer, o que eu queria contar era a minha história, sem a contar e, portanto, escolhi o romance para fazer isso, mas, no fundo, era pressionada pelo que eu tinha cá dentro e aquilo que me apareceu aqui, na altura, que era o Lobo Antunes, o José Saramago, o Cardoso Pires, o João Melo, ou a Teolinda Gersão, ou a Hélia Correia, ou o Almeida Faria, o Mário de Carvalho.

Quer dizer, o que nós pretendíamos, na altura, era cada um dar vazão a uma visão, só que agora, olhando para trás, nós pensávamos que não estávamos inscritos numa [escola], mas estávamos, não é? Estávamos inscritos numa geração, quer dizer, fazíamos parte duma geração; portanto, a transfiguração era pessoal, mas as nossas raízes eram dum tempo determinado. Então volta-se para trás e percebe-se que nós pertencemos a um período em que a questão do país - e a questão da mudança do país - acabou por ter uma importância muito grande, e vê-se isso, sobretudo, quando se percebe qual é o imaginário dos mais jovens hoje, não é, quando se percebe que seu imaginário vai noutra direção, não é, e então, percebe-se que nós estamos num tempo que corre, no nosso tempo, não é?

MD: No ensaio $A$ morte de Portugal, Miguel Real faz duas afirmações importantes: a primeira, ao discutir a conjuntura político-econômica atual de Portugal, é que os governos recentes têm dado cabo do que a Revolução conquistou para grande parte da população portuguesa, que muitas vezes não tinha acesso ao mínimo básico de saúde, ou de educação, e que essas foram conquistas que vieram com os governos pós-25 de Abril. A segunda é a seguinte: ele diz que, para que Portugal se reencontre, mais uma vez, é preciso, de novo, matar Dom Sebastião. Portugal não matou Dom Sebastião ainda? Ou Portugal precisa mesmo matar Dom Sebastião?

LJ: Não concordo com a primeira, é muito simplista a primeira visão, mas a segunda, acho que sim, acho que não matou ainda Dom Sebastião. Ainda, Dom Sebastião foi transferido, no nosso caso, para as instâncias europeias, isto é, dissemos "Nós, sozinhos, não somos capazes”. E isso, fizemo-lo duma forma legal, legal “à portuguesa”, isto é, aceitando, como outros países, uma ajuda, obrigando-nos a cumprir prazos, obrigando-nos a uma espécie de "cadernos de encargos de seriedade", e, sobretudo, de horários e de agenda, de 
que nós, em geral, dilatamos muito tempo, e, portanto, não cumprimos, e a Europa obrigou-nos a uma espécie de seriedade nesse domínio.

Portanto, era uma espécie de Dom Sebastião, salvador, mas que nós víamos de uma forma legal, duma forma como um compromisso internacional, político. O que acontece é que a degradação das contas públicas levou-nos a que nós, agora, tivéssemos Dom Sebastião outra vez cá dentro, o que é uma grande dor, e isso eu acho que é talvez o que mais custa aos portugueses neste momento, conscientes da situação, é percebermos que somos um território ocupado, mentalmente ocupado, a ideia de minoridade mental que nos foi passada, a ideia de que Dom Sebastião, pois, veio sim, quer dizer, que só nos conseguimos libertar, salvar, porque ele está aqui com as botas de cortiça, compreende? E isso, portanto, é alguma coisa que nos custa muito. Agora, a minha ideia é esta: há uma mudança muito grande no mundo neste momento, tão grande, tão grande, tão grande que não sei até quando é que vamos pensar nestes termos, até quando é que as administrações, até quando estes parâmetros, que são os da minha fala, os de Miguel Real, ou talvez ainda as suas, eles vão servir de ligação; esta nossa linguagem, estas nossas categorias mentais, elas vão sobreviver a uma coisa que está sendo vasta, uma nova cultura a que nós estamos a assistir nascer sobre os nossos olhos, não é?

É incrível: as culturas locais, as culturas nacionais são alguma coisa que tem de caminhar ao lado de culturas econômicas globais, muito mais vastas. E nós estamos numa luta entre uma espécie de incapacidade de compaginar aquilo que queremos ser, como herdeiros de uma cultura, de uma língua própria, de um espaço próprio, daquilo que nós chamamos nações, e, por outro lado, interesses que a economia global obriga a desmembrar. Aqui, portanto, estamos a viver dois momentos, em simultâneo, e, não sei, sou franca, não sei como se vão ultrapassar. Sei é que têm de viver com aquilo que ele tem dentro, vendo que eu não quero perder aquilo que nos caracteriza, e quero que o que nos caracteriza, de forma positiva, como é o caso da convivialidade portuguesa, que é uma coisa muito positiva no mundo de hoje. 
MD: Uma das passagens de $O$ dia dos prodígios que mais me impressionaram quando li o livro pela primeira vez, e pela segunda, e pela terceira, é a cena em que os soldados de Lisboa falam o que foi a revolução, ou o que se pretende com ela, e em que, para os habitantes da aldeia, tudo gira em torno da solução do grande enigma do réptil alado. Uma primeira leitura pode sugerir que tenha sido uma maneira de dizer, "olha, primeiro, a revolução não chegou aqui; segundo, ela está chegando agora para nós não é importante. A gente precisa de coisas mais imediatas e básicas". Depois de ouvi-la, vem-me à cabeça a ideia de que essa cena, na verdade, tenha sido escrita no diapasão oposto, ou seja, "foi mágico, sim, e foi tão providencial, que nós ainda não nos demos conta disso". Pode ser assim?

LJ: Pode ser, sim, pode ser, sim. Que não nos demos conta disso, claro. Eles vêm dar uma explicação política, dizem "a partir de agora, vai ser ...". E, de facto, eles dizem "não, espera... Nós queremos mais alguma coisa”, não é? Eles queriam do domínio do ontológico, do sobrenatural, há um desencontro de linguagens, não é? Quando eles mostram as figuras do Marx, do Lenine, eles veem as figuras dos santos, e quando eles saem, eles dizem, "nós tivemos uma visão, gente”. Quer dizer, é essa mesma a visão, eles têm a ideia de que alguma coisa os transcendeu, mas não sabem o que os transcendeu, não é? Há, portanto, uma apreciação imperfeita do que aconteceu, quer dizer, eles foram actores de uma acção que não são capazes nem na menor medida de interpretar.

MD: Pensando no conjunto dos seus romances, desde $O$ dia dos prodígios até $A$ noite das mulheres cantoras, julga que as questões de fundo estejam ali sempre e tenham tomado novas formas, ou foram sendo resolvidas e substituídas por outras? Minha pergunta, basicamente, é: é possível dizer que a sua obra de romance discuta, toda ela, questões ligadas à sua perspectiva do que foi o 25 de Abril ou não?

LJ: Não, é mais vasto do que isto. É mais vasto. Acho que o que une, deste ponto de vista, todos, inclusive este último, é mais a questão da mudança que se verificou no país e no mundo, mas como a mudança do país se repercute no mundo e de que maneira nós somos agentes dessa mudança, somos agentes ativos e agentes passivos desta mudança. Acho que nada está resolvido em nenhum dos meus livros, nenhum dos problemas que foram levantados desde o princípio, eles estão resolvidos, não estão resolvidos. Há uma 
dissincronia entre aquilo que é posição problemática que os livros levantam e a sua realização na prática, na história, não é? É que eu escrevo sabendo que tenho este problema de ser, sobretudo, digamos, uma escritora envolvida com o social. Encanta-me. Eu começo por ser ontológica, mas quando dou por mim, o meu ontológico passa para o social. Mas a verdade é que meu único parâmetro de conduta é este: como é que eu escolho os temas, como é que eles me vêm parar, apenas isto, numa ambição de ser testemunha do tempo, compreende? Por isso que eu nunca escrevo nada histórico, eu escrevo, posso escrever sobre aquilo que se torna história, o que é bastante diferente, não é? Porque o que me interessa é isso, é ser testemunha de um tempo. Portanto, na verdade, minha ambição é ser o escritor que, para o seu país, ajudasse a criar, não digo eu, mas que ajudasse a criar, que pertencesse a uma geração de escritores que deixassem uma marca, no domínio da fantasia e da arte, dissesse "essa gente, na altura, viveu assim e sonhou que poderia ser assim”, compreende? Como o Kundera faz em relação ao seu país, em relação à República Tcheca, como, enfim, como a Margarite Youcenar o fez em relação à Europa, porque ela foi mais global, não é? Ou a Marguerite Duras fez em relação à França, a ideia, que é aquilo de que eu gosto nos outros escritores, quer dizer, os escritores que me interessam são aqueles que são profundas testemunhas do seu tempo, que não fugiram do seu tempo, compreende?

MD: Em $O$ dia dos prodígios e $O$ cais das merendas, apresentam-se duas situações em que o individual se funde ao coletivo de uma maneira quase inseparável, ainda que sejam os indivíduos muito bem caracterizados, com seus dramas, dores e alegrias, a vida do conjunto parece sobrepor-se à vida do indivíduo; por outro lado, Notícia da cidade silvestre, por exemplo, apresenta Júlia Grei mais envolvida com seus dramas do que consciente da vida de grupo, da mesma maneira que acontece em O jardim sem limites, em que pessoas envolvidas em projetos das mais variadas ordens participam de um grupo, de uma geração de pessoas que vivem ali as contingências políticas, econômicas, sociais, mas floresce o individual a partir desse momento, o que é ainda mais evidente em $O$ vale da paixão. A certa altura dessa conversa, você falava sobre o fato de "sim, a motivação é ontológica, e, quando eu vou ver, esse ontológico, vai esbarrar no social, não é?” Ou “sim, a minha necessidade quando eu pensei, lá no começo, em 
O dia dos prodígios, era falar do que eu trazia e sentia e via no mundo ao meu redor". Pode-se pensar nessa questão assim?

LJ: Pode pensar, sim, pode pensar. O social nunca desaparece, a forma de ele entrar é que é diferente, não é? Foi uma espécie de escolha, a partir da Notícia da cidade silvestre, que eu fiz, que muita gente lamenta que eu tenha feito, mas, assim, nesses dois primeiros livros, eu foquei uma realidade onde o colectivo era fácil de tratar daquela forma, que era uma realidade rural, porque havia um poético do colectivo, porque, como hei de dizer, eu estava lá por amor, mas não estava como personagem, compreende? Só que, a certa altura, interessante, quando eu escrevi estes dois livros, muito bem aceitos, foi uma questão de coerência, sabe? Houve quem pensasse, ainda hoje há quem pense, que eu criei uma espécie de oportunidade, mas eu percebi, não foi oportunidade que eu criei, foi uma questão de coerência absoluta, eu percebi que eu tinha uma outra linguagem, urbana, a linguagem da minha própria vida, que não era só a da vivência rural, grupal, dos grande grupos que falam, todos por uma voz, digamos, em que a matriz bíblica estava muito presente. Eu tinha uma outra visão, moderna, no fundo, contemporânea, da voz do homem isolado que interpreta o colectivo, que sabe pelo seu produto, também, e que age pelo colectivo, mas que age pela dor forte e sua esperança forte estão sempre a dizer “sim”. Eu, a partir daí, enveredei por esse campo, em que o colectivo aparece, aliás, A costa dos murmúrios tem esse colectivo. Agora, há uma coisa que acontece: eu gosto, e há os meus livros que eu prefiro mais, os que eu prefiro menos, não é, mas eu diria que, do ponto de vista do tratamento colectivo, aquele em que eu consegui melhor fazer isso foi $\mathrm{O}$ dia dos prodígios, aquele colectivo, eu consegui, penso que consegui, tratá-lo, depois a fusão entre o colectivo e o individual, parece-me que está bem feito, e que está, que é orgânico, em A costa dos murmúrios, e acho que há um livro - esta é uma apreciação minha, mas... - onde a imagem do coletivo não precisa de lá estar, porque a figura, digamos, humanizada e intensa, se firma, que é a de Milene, de $\mathrm{O}$ vento assobiando nas gruas. Quer dizer que houve, portanto, uma espécie de mudança, não é? Eu gosto de muitas, talvez já não volte àquele individual, grupal em o indivíduo não existe, como é o caso de $\mathrm{O}$ dia dos prodígios, existem indivíduos, mas as figuras estão esbatidas em grupos, talvez não volte mais assim, 
porque as realidades são outras, mas nunca me sinto satisfeita quando escrevo um livro, chego ao fim e, como hei de dizer, as figuras não trouxeram um remanescente suficientemente forte do grupo que as envolve.

MD: De um lado, Branca Volante, as Carminhas [personagens de $O$ dia dos prodígios], a Miss Laura, a Santanita Trigal, a Rosária, a Valentina Palas [personagens de $O$ cais das merendas], a Júlia Grei [de Notícia da cidade silvestre], a Evita [de $A$ costa dos murmúrios], a Maria Ema [personagem de $O$ vale da paixão] e a Susana [de O jardim sem limites]. Do outro, eu tenho a Jesuína Palha [de O dia dos prodígios], a Pinaira, a Zulmira Santos [personagens de $O$ cais das merendas], a Anabela Cravo [de Notícia da cidade silvestre], a Eva Lopo, a Helena [ambas de $A$ costa dos murmúrios], a narradora de O vale da paixão, cujo nome não está, e a Paulina, de O jardim sem limites. Pelo menos em um dos lados desta tabela, aparecem mulheres cuja palavra é poderosa demais. Por exemplo, toda a movimentação de Vilamaninhos, em grande parte, gira em torno do que diz Jesuína Palha. Ela é a voz coletiva mais forte, ali. Da mesma maneira, há momentos de tensão em $O$ cais das merendas em que é Pinaira quem está lá suscitando a briga, a discussão, o desconforto; é Eva Lopo quem retoma uma narrativa muito diferente daquela que Evita apresenta na primeira parte de $A$ costa dos murmúrios; a vida de Júlia Grei é orientada por Anabela Cravo por meio de tudo o que ela diz, e aí, eu escrevi quatro palavras aqui, que sintetizam, para mim, essa relação: mulheres, palavras, bálsamo e veneno.

\section{LJ: Risos...}

MD: Essa relação entre mulheres e palavras na sua obra me fascina. Mais do que simplesmente a questão da mulher, mulheres e palavras...

LJ: Aquela que diz. Aquela que vê e que diz, não é? A que profere o discurso. A que desencadeia. Isso me faz lembrar o seguinte: (aqui, a voz de Lídia Jorge assume um tom grave, quase solene) nesse momento, não sei se sabe que Agustina Bessa-Luís está muito doente em casa, e eu tenho muita saudade dela, porque ela era uma figura com a qual eu contrastava imenso, imenso, tínhamos poucos pontos de contacto, mas estar com ela, para mim, era um fascínio, eu adorava estar com ela. E para ela era também, porque ela tinha a ilusão, penso que é uma ilusão, de que eu era uma pessoa muito doce, muito conduzível, e 
que ela me conduzia. E ela gostava imenso desse papel. Não era verdade, quer dizer, eu deixava-me conduzir no que eu queria, não é? Pois então, ela uma vez disse uma coisa e acho que o disse no Brasil. Perguntaram-lhe - eu tinha acabado de aparecer, penso que tinha dois ou três livros ainda publicados - o que é que ela achava e ela disse: ah, sabe, a ela, para ser uma grande escritora, falta-lhe perversidade (risos). E isso ecoou, tivemos grandes embates públicos, de ponto de vista, quer dizer, e ela sempre me dizia que as minhas personagens eram frágeis, que as mulheres eram frágeis, e eu dizia-lhe, não, eu dizia, mais frágeis eram as dela, “mais frágeis são as suas, as suas aparecem como figuras do poder, já as minhas aparecem como figuras do olhar, aquelas que observam, e que observam o poder, também, e observam o poder das outras, quer dizer, não lhes interessa o poder das suas, as suas são mulheres poderosas que querem derrubar os homens, que derrubam os homens”. Ora, eu estou num outro patamar, são mulheres que podem derrubar, ou não derrubar, não é isso que interessa, o que interessa é que elas são sagazes do ponto de vista do olhar, elas veem tudo à volta, elas aparecem nos livros porque elas são porta-vozes dum saber que vai muito para além delas. Portanto, como hei de dizer, não estou a reivindicar melhor literatura, nem pior literatura, estou a reivindicar diferenças de olhar sobre, de papel, diferenças de papel no interior do livro. A Agustina tem uma escrita poderosa, as figuras parecem que são levadas por ela, são prolongamentos dela, digamos, do poder, são mulheres que vencem, são vinheteiras, mulheres do mundo do Norte, que vêm e dominam, que sabem, que conseguem dominar os outros no ter, no haver, no domínio da família, no domínio do amor etc. E a divisão que faz aí é uma divisão que, a princípio, pensei "é aleatória”, quer dizer, estão umas, estão outras, mas não é aleatória, umas suscitam de uma forma, outras doutra, umas são centro, que vê, que irradia um saber, um conhecimento à volta, e outras vêm a suscitar, vêm àquele lugar dizer "não, isto não é assim", vêm contrapor, vêm colocar uma outra forma de questionamento às primeiras, não é? De forma que eu agradeço essa visão, porque é uma visão que se compagina muito mais comigo do ponto de vista do papel da mulher. Tem gente que diz, “ah, mas tu não és feminista”. Quando eu comecei, veio uma jornalista francesa e disseme "sabe, as feministas dizem que a escrita da Lídia não tem sexo”. Eu disse "Mentira! Tem! O que tem é no olhar. Eu não preciso de estar a explicar como é que as mulheres 
dormem e o que sentem, isso não me interessa. Me interessa é o saber que elas têm, como elas encaram os outros, as outras figuras. E $\mathrm{O}$ vento assobiando nas gruas considero, deste ponto de vista, é o livro mais importante. Porque é o livro em que a figura feminina... Sei que ele é maçador de ler, para alguns leitores, porque é lento, demasiado lento, e assim. Mas é o livro em que a personagem declara que não tem as palavras para o mundo. E já tem sido interpretado, e eu acho que têm razão, a princípio eu não percebi isto, mas ela é uma espécie de simulacro daquilo que é o próprio escritor. Quer dizer, no meio destas figuras todas, ela é aquela que vem dizer assim: "por mais que eu queira, não consigo explicar o mundo; ele passa-me ao largo porque não tenho as palavras todas".

Quer dizer, é a própria personagem a ver o poder, a falar sobre o poder da palavra, compreende, a declarar que não tem as palavras todas, mas mesmo que as tivesse não usaria para determinadas situações, porque elas inauguram coisas, a palavra dita, proferida, ela inaugura alguma coisa, então, eu tenho a ideia de que, interessando-lhe essa perspectiva, era bom dar uma olhada nessa passagem, que é fulcral para isso, quer dizer, a figura feminina que põe em si a questão da linguagem, do pensamento que não abarca a realidade e, portanto, aquela que nasce para dizer "eu não tenho as palavras", compreende?

MD: Duas mulheres destas que eu listei me vêm à cabeça, quando você me diz isso, as duas do mesmo romance, inclusive, são a Julieta Lanuit e a Paulina [de O jardim sem limites], que tomam ali algumas atitudes que muitas vezes vão contra determinados valores que elas mesmas apresentam, especialmente a Julieta, que tem de vencer uma barreira própria em nome do que ela julga ser o bem que ela faz para o Eduardo, e a Paulina, que, em um primeiro momento, parece ser uma mente manipuladora e que tem um interesse muito concreto, muito específico na atuação do Leonardo, mas que também deixa transparecer que, de fato, existe ali uma preocupação genuína dela em relação a ele, “eu tenho de ajudá-lo, eu tenho de fazer por ele”, por mais que ela também seja a mulher que vá correr atrás dos patrocinadores e que, de certa forma, institua todo o palco para o espetáculo grandioso do Leonardo. E, a meu ver, ela vem ao encontro disso que você está dizendo, não é, quer dizer, não são anjos, nem demônios, não há bálsamo, nem veneno na Paulina, isso fica muito visível nessas personagens... 
LJ: A cena em que a Julieta se resolve pôr à mesa, como vítima... Isso, do seu ponto de vista, quando ela diz “agora, comam-me”, não é, “eu não consigo mais trabalhar”, pois seu marido não consegue, não é, então, ela põe-se, oferece-se como refeição. E como têm dito que é um momento operático e assim, mas incluiria no bálsamo ou no veneno?

MD: Eu acho que eu incluiria no bálsamo... Com uma pitada de veneno (risos)

LJ: Com uma pitada de veneno... (risos) Porque, no fundo, ela é uma oferta, é uma oferta, uma paixão crística, não é?

MD: Para mim, foi o elemento que ficou mais evidente nessa cena... Não sei se a minha leitura também não é uma leitura ingênua...

LJ: Não, não é ingênua, não é ingênua, não... De modo nenhum, de modo nenhum... Pra ver que, quando eu escrevi isto, não pensei em nada disso, quer dizer... Eu acho que percebe muito bem porque o leitor, quando olha, quando lê, precisa de fazer um esforço para perceber quais são os outros significados, não é... E assim é quem escreve... Quem escreve é como quem lê, está em um certo precedente, que é igual, é idêntico, mas escrevese porque se tem vontade daquilo, quer dizer, aquela imagem apareceu-me... Quando eu comecei a escrever a história da Lanuit, eu queria chegar àquele ponto, quer dizer, aquela mulher, que se colocava com os candelabros no meio da mesa... Comei de mim, comei de mim, que é uma visão crística... Aliás, penso que é um mito poderosíssimo da cultura, e que é, antropologicamente, de uma força brutal, praticamente inultrapassável, esta ideia do sacrifício pelo outro, o sacrifício total do outro... É muito difícil de ultrapassar, uma vez que a gente não sabe se aconteceu, mas que se diz que aconteceu...

Então, eu acho que não se consegue fatigar isto nas literaturas, agora, tem, passa por uma visão que está forte, sobretudo em nossas culturas, é impossível de retirar. Eu vejo muito isso no sexo, que é muito presente na literatura brasileira, muito, muito forte, muito forte, muito forte, muito forte, digamos, do ponto de vista da exibição sexual, os portugueses devem parecer uns pudicos, gente de sacristia junto dos brasileiros, não é? Eu acho que não se faz não é por pudor, é porque a cultura não precisa... Quer dizer, nós não 
entendemos que é importante, que é artisticamente funcional, compreende? Não tem nem com pudor, nem com coisa nenhuma destas, mas grande parte da cultura, quer dizer, da literatura erótica brasileira, eu leio-a como crística, digamos, há toda uma série de sofrimentos e de superação, de dor e de tudo isso, e de repúdio, quer dizer, de todos os sentimentos em torno da questão sexual, que é espantoso. Um jornalista, há dois anos, publicou uns contos sobre, que foram premiados no Brasil, todos sobre sexo, e é duma dureza enorme, brutal, brutal. E é tudo crístico, sabe? Nunca se fala lá, mas é, digamos, a vitimização, a descida a uma espécie de inferno sexual, que tem a ver com isso, não é? Que tem a ver com isto que nós estamos a dizer, a questão da vitimização está muito presente na nossa cultura, ao contrário dos romances... Muito bem, tenho eu perguntas para lhe fazer...

MD: Por favor... Desligo o gravador então, agora, muito obrigado, não tenho nem o que lhe dizer mais, para agradecer todas essas coisas que você me disse.

TEMPO TOTAL DE ENTREVISTA: 1h, 32 min, $22 \mathrm{seg}$.

Transcrita entre os dias 01 e 21 de agosto de 2012, esta entrevista foi realizada em 25 de julho de 2012, na "Casa das Courelinhas”, residência da mãe de Lídia Jorge, em Boliqueime, na região do Algarve. 